\title{
Paideusis
}

\section{Open-minded Environmental Education in the Science Classroom}

\section{David P. Burns and Stephen P. Norris}

Volume 18, Number 1, 2009

URI: https://id.erudit.org/iderudit/1072337ar

DOI: https://doi.org/10.7202/1072337ar

See table of contents

Publisher(s)

Canadian Philosophy of Education Society

ISSN

0838-4517 (print)

1916-0348 (digital)

Explore this journal

Cite this article

Burns, D. \& Norris, S. (2009). Open-minded Environmental Education in the Science Classroom. Paideusis, 18(1), 36-43. https://doi.org/10.7202/1072337ar
Article abstract

In this paper we will discuss the issue of environmental advocacy in science education in light of William Hare's concept of open-mindedness. Although we shall assume that science teaching and learning must go beyond the scientific facts and theories and deal with the implications of science for society, we shall argue that science education should also demand an open-mindedness about environmental concerns such that all proposals for sustainability and the like are weighed against the alternatives using the best scientific knowledge available. Our approach will be to describe two examples of environmental education that recommend insufficiently open-minded forms of teaching and a third example that avoids this shortcoming yet provides a sound basis in environmental education. (c) David P. Burns, Stephen P. Norris, 2009

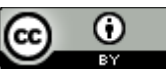

This document is protected by copyright law. Use of the services of Érudit (including reproduction) is subject to its terms and conditions, which can be viewed online.

https://apropos.erudit.org/en/users/policy-on-use/ 


\title{
Open-minded Environmental Education in the Science Classroom
}

\author{
DAVID P. BURNS AND STEPHEN P. NORRIS \\ University of Alberta, Canada
}

\begin{abstract}
In this paper we will discuss the issue of environmental advocacy in science education in light of William Hare's concept of open-mindedness. Although we shall assume that science teaching and learning must go beyond the scientific facts and theories and deal with the implications of science for society, we shall argue that science education should also demand an open-mindedness about environmental concerns such that all proposals for sustainability and the like are weighed against the alternatives using the best scientific knowledge available. Our approach will be to describe two examples of environmental education that recommend insufficiently open-minded forms of teaching and a third example that avoids this shortcoming yet provides a sound basis in environmental education.
\end{abstract}

Attempts to foster particular attitudes about the environment are prominent within the curricula of many subjects in the contemporary school. In this paper we will argue that, although science may contribute to the goals of environmental education, science education should not be involved in furthering particular, contested assumptions and propositions. We argue that it is not appropriate to expect science educators to advance contentious agendas — some of which conflict with science-and that educators and scholars should be concerned to keep apart such efforts and science education. This argument will be constructed in four stages. First, we will outline the broad nature of the positions within environmental education that we seek to critique. Within this section we draw a distinction between those approaches that seek to endorse particular values and those that seek to make such values the subject of fundamental debate within science classrooms. Second, we will introduce Hare's concept of open-mindedness as an analytic lens for examining approaches to environmental moral education. Third, we will focus this lens on two examples of recent environmental education scholarship and will demonstrate that these examples insufficiently display an open-minded form of science education. Fourth, we will identify a form of open-minded environmental education that avoids the pitfalls of the examples identified previously and that still provides a sound environmental education.

\section{Values and Environmental Education}

There are many understandings of environmental education. Several related terms-e.g., "environmental education," "ecological education," "sustainability education"-all carry vague but related meanings. Environmental education, as the name implies, adopts a specific focus on the

(C) Copyright 2009. The authors, David P. Burns and Stephen P. Norris, assign to Paideusis the right of first publication and educational and non-profit institutions a non-exclusive license to use this document for personal use and in courses of instruction provided that the article is used in full and this copyright statement is reproduced. Any other usage is probibited without the express permission of the authors. 
environment (see Chawla \& Flanders Cushing, 2007). Ecological education pursues some form of ecological valuing or disposition (see Nuyen, 2008). Sustainability education has functioned to promote effective and lasting use of the environment as a set of resources (Bonnett, 2007). These different approaches have produced significant and fruitful discussion in environmental education journals.

Our attention will be directed towards the difference between those forms of education that endorse and promote particular values with respect to the environment and those that do not clearly advocate for a set of values, although they may inform value reasoning about the environment. The former type of education may advance particular views of the moral status of the environment, particular notions of the correct human relationship to the environment, or particular views of how humans ought to use the environment or view their impact on it. Those approaches and arguments that promote particular environmental values we will refer to as value-endorsing approaches to environmental education, and those that do not will be referred to as non-value-endorsing approaches to environmental education.

Contemporary scholars of environmental education tend to agree on several general principles. For example, it is commonly stated that environmental education ought to play a role in preparing students to ask and to answer critical and informed questions on matters for which scientific evidence or perspectives are relevant. Pedretti and Little (2008) note that science itself is at least partially about asking critical questions. Bonnett (2007) argues environmental education ought "to bring a range of searching questions concerning nature to the attention of learners, and to encourage them to develop their own on-going responses to those questions" (p. 709). Jickling and Wals (2008) emphasize notions of autonomy, active citizenry, and criticalness in characterizing the goals of environmental education.

Within science education, several scholars have advocated a goal of intellectual independence aimed at teaching students to make informed personal decisions when science is relevant (Aikenhead, 1990; Kitchener, 1992; Munby, 1980; Norris, 1997). Approaches that foster this sort of preparation could fairly be labeled non-value-endorsing, in that they advance a position that seeks to place key decisions in the hands of students. Although all teaching rests upon values, such approaches seek to minimize the extent to which teachers answer important ethical or social questions for students. The boundary between value-endorsing and non-value-endorsing is clearly and substantially transgressed in many of the currently proposed environmental education approaches being pressed upon science education classrooms. Consider these two examples from recent literature in environmental education:

A: "Education for stewardship... aims to heighten appreciation for all forms of life and for Earth as the only life-sustaining environment we know." (Pedretti \& Little, 2008, p. 39)

B: "What educators can influence are students' opportunities to gain knowledge, form positive attitudes about the environment, and practice action skills.” (Chawla \& Flanders Cushing, 2007, p. 441)

In each of the above the authors are taking an extra-scientific position with respect to the status of the environment. By extra-scientific we mean that the position is not a scientific conclusion, scientific evidence, or otherwise part of science proper. Positions are being advanced that seek to charge science education with fostering a particular disposition toward the environment. Although the authors do not fully define what they mean by "appreciation for all forms of life" and by "positive attitudes about the environment," it is clear from their discussion that they are promoting a kind of valuing of the environment. Indeed, Chawla and Flanders Cushing (2007, p. 439) draw upon research into environmental activism to help determine how students can be pressed to activist dispositions.

Positions similar to these on the status of the environment are advanced across a spectrum of educational issues. It has been argued, for example, that teachers should be subject to sustainability training in their pre-service education (Ferreira, Ryan \& Tilbury, 2007). It is commonly proposed that students ought to have a relationship with the environment as they would with a person and that this relationship can be somehow threatened by failing to interact with, or develop feelings towards, the 
environment (e.g., Blanchet-Cohen, 2008). Others take more extreme positions, and, as in the case of Bonnett (2007), advocate for particular spiritual or metaphysical positions which relate the state of the environment to the "spiritual survival" (p. 719) of humans. Although there is some disagreement within the field, as in the case of the debate between sustainability education and other forms of environmental education, one finds a willingness that concerns us to press moral and ethical conclusions about environmental problems into curricula and policy while concurrently claiming to support decision-making models of science education that leave critical questions open to students' judgments.

Value-endorsing programs are strongly supported internationally. They are promoted by the United Nations (UNESCO, n.d.), and benefit from pressure being placed on schools by governments (Eames, Brownwen, \& Bolstad, 2008; Jickling \& Wals, 2008). Environmental activist organizations have explicitly targeted schools (Stoss, 2008), and their potential power within education is clear.

\section{William Hare and Open-mindedness}

Open-mindedness is revealed in the manner through which we form and hold our beliefs (Hare, 1979). "Open-mindedness is that attitude of the mind which is present when a person is disposed to form and revise her or his view in the light of evidence and argument" (Hare, 2000, p. 91). Open-mindedness, thus conceived, is an ideal. One need not believe in the final achievability of total open-mindedness in order to find it valuable and for it to serve as an educational goal (Hare, 2000). It may very well be impossible to be fully open-minded. This does not mean, however, that one must "declare it a complete illusion" (Hare, 2000, p. 96). Indeed, all virtues manifest as goals that are worthy but yet are unlikely to be achievable. Aristotle himself did not expect the practicing of virtue to be easy (Aristotle, 1953, 1106b30). Open-mindedness is neither neutral (Hare, 1979) nor relativist (Harding \& Hare, 2000). That is, there is nothing inconsistent between being open-minded and taking a stand and forming strong beliefs. All that is required of open-mindedness is that the stand and beliefs be founded on evidence and argument and that the agent be willing to change should additional evidence and argument point that way. The open-minded agent is to be contrasted with one who is "incapable of thinking of any objections to his own position, or of recognizing any merit in contrary points of view," (Hare, 1979, p. 8) or one who is simply "unwilling to attend to such arguments" (Hare, 1979, p. 8). Poor education may contribute to the kind of person who is incapable of open-mindedness by instilling a close-minded disposition that renders one obdurate in the face of alternative points of view.

Hare has argued that in order to be open-minded a person must be "both willing and able to revise his own position" (Hare, 1979, p. 8). He posits that open-minded persons have a set of dispositions that enable them to take seriously new ideas, and to consider seriously critiques of currently held ideas. One must, for example, pay attention to and take properly into account arguments and evidence that contradict currently held positions.

Hare makes a series of comments that are quite directly applicable to our current discussion. Scientists may be expected, Hare (1979) argues, to actively search for evidence to contradict their assumptions and conclusions. Perhaps most interesting from our perspective, Hare urges that teachers need to "dislodge any tendency students might have to accept ideas on the basis of sheer authority or favored status" (Hare, 2000, p. 92). Similarly, he argues that it is necessary to see "what is conventionally deemed straightforward as potentially problematic" (p. 91).

These claims should not be interpreted to mean that educators ought to avoid openly stating their positions on issues. Rather, teachers, if careful, may quite profitably be able to explain to students their positions on issues (Hare, 2002) if they do so with the intent of showing how one comes to a defensible position and with the caveat that their positions may be revised in the face of new insights. Thus, a teacher taking a position in class is not in and of itself close-minded. The key to Hare's analysis 
is that teachers be in a position where they are both open to revising their own beliefs and fostering this disposition and practice in their students.

It is the capacity to respond with open minds to changing circumstances that calls into question the proposed practices we identified in the previous section. Our aim is not to argue whether we ought to value the environment in one way or another, or to ask whether the environment is worthy of any particular moral status or another. We do not seek to defend, or even consider, any particular position on such issues. Our aim is to argue that since these questions must arise in a critical science classroom, and because they are so clearly open to serious contestation, they ought to be treated in an open-minded fashion. We will demonstrate that the value-endorsing environmental education literature we have examined is insufficiently open-minded. Our demonstration will rely on a number of indicators of open-mindedness that Hare introduces. These criteria include: critically questioning popular or accepted positions, seeking counter-evidence to one's own position, taking conflicting positions or evidence seriously, and willingly revising positions. Whether aiming for broad scientific literacy or training future scientists, it is clear that students should not be taught to accept positions on the basis of their popularity. Rather, they ought to be taught to accept positions on the basis of their rational and empirical strength.

\section{Applying Open-mindedness to Environmental Education}

Our application of Hare's ideas will focus on two recent examples of value-endorsing approaches: Pedretti and Little's short resource book From Engagement to Empowerment: Reflections on Science Education for Ontario (2008), and Bonnett's article Environmental Education and the Issue of Nature (2007). Pedretti and Little's text is a ninety-four-page resource created for practicing teachers, administrators and other educational leaders. Its stated focus is the "role of Science, Technology, Society, and the Environment (STSE) in fostering Scientific Literacy for all students" (p. 2, bold text in original). Within it, the authors provide a broad reflection on the need for STSE-focused science education and the relationship of such a focus to other important educational issues such as cultural diversity and personal empowerment.

The authors have clearly taken significant steps to ensure that they do not advance a narrow version of science education. They indicate early in the text that their "particular view of science and science education ... may not be held by all" (p. 4). At numerous points in their discussion they remind the reader that the central focus ought to be a form of critical scientific literacy in which students are empowered to make and act upon important personal decisions. In doing so, their vision seeks to move beyond "value-free" (p. 42) views of science that do not clearly engage important ethical and civic considerations (p. 21). They recognize that this engagement involves deeply contested values and that this contestation poses critical problems for educators (p. 43).

However, as Pedretti and Little detail their vision for STSE education, they casually introduce important moral educational ideas and positions into their discussion that warrant substantial philosophic analysis. Take, for example, their discussion of values and science education. They assert that "values education should be a part of science education" (p. 25), and subsequently ask "what are the values I want clarified for my students?" (p. 25). Whether or not these references are conscious invocations of the moral educational approach known as values-clarification is unclear, and it would be unfair to critique them on this basis alone. But the passing way in which such a fundamental array of moral-ethical issues is raised is cause for concern. Indeed, when one pays close attention to the moral educational language employed in this text, it becomes clear that many of the key ethical questions Pedretti and Little seek to leave with students are being subtly answered in advance.

For example, after surveying a series of studies and policies regarding stewardship, the authors assert that "the ultimate aim is for every citizen to have formulated for him- or herself a responsible attitude toward the sustainable development of Earth, an appreciation of its resources and beauty, and 
an assumption of an environmental ethic" (p. 40). While this statement is presented as arising from the broad array of policies and studies cited in the preceding pages, it advances clearly contentious positions. First, it is not clear that sustainable development is itself an appropriate educational goal. Indeed, Bonnet (2007) critiques precisely this assumption. Second, it is philosophically significant that, prior to permitting students to assume an environmental ethic (their own environmental ethic, presumably), the authors note that they must appreciate the Earth for its resources and beauty. Given that the appropriate human relationship to and disposition toward the environment are central questions within an environmental ethic (Gruen, 2003; Brennan \& Lo, 2008), it is dubious to claim that this proposition advances student decision-making. In other words, given that the moral status of the environment is an unsettled philosophical issue, it is not clear that Pedretti and Little's emphasis on sustainability and appreciation is an appropriate limitation on the values of students.

By presenting these arguments as largely uncontroversial, this text provides a misleading picture of the moral educational context of environmental education. The authors note that "the history of environmental education (and traditional school science) is checkered, [and] fraught with political and ideological tensions and debates" (p. 38), but instead of taking the opportunity to introduce the diversity of differing positions, the authors appear to find such discussions unnecessary to their task. Sustainability and stewardship are taken to be uncontroversial and compatible. When the vital distinction between education for the environment and education about the environment is raised, it is left unexamined (p. 40). Without argument that advances the authors' position in light of the key debates, the teachers using this text will be left to accept these assertions on the basis of the authority of Pedretti and Little, and the generally like-minded authors they cite.

What, in addition, could we say about these positions using Hare's insight? First, it must be recognized that the position Pedretti and Little advance is legitimate. Indeed, one may link it to several plausible and popular philosophic arguments (though these arguments are not meaningfully rehearsed or cited in the document in question). The problem, however, lies in how such beliefs are held and how they are hoped to influence the reader. If the reader agrees with the given ethical position it will be a result of either having held that position previously or having simply accepted the authors' assertion as correct on the basis of its having been accepted by the authors. In the absence of an explicit argument and reference to counter-positions, the authors leave one to accept their position as a result of its supposed popularity. In this sense such literature clearly fails to foster open-mindedness about the fundamental ethical questions at stake.

Bonnett (2007), who strongly disagrees with the sustainability agenda, promotes similar thinking. He begins his article with a critique of the dominant anthropocentric, "analytic/instrumental/invasive rationality" (p. 708) that he believes dominates science education. He provides a similar critique of the sustainability movement. In response to the inadequacy of these constructs, he proposes that environmental education teach students to view nature as "self-arising" (p. 712). In other words, students need to recognize that nature has its own existence and that, crucially, the beings humans encounter in nature present themselves as neither fully controllable nor fully knowable (pp. 712-3). He notes, “... the appropriate response to self-arising nature then is not to seek summative knowledge, but to allow a sense of the ineffable" (p. 713). The search for summative knowledge describes both his view of science and his critique of it. Extending this view, he later notes that "We know what it is like to be a human being in a way in which we cannot know what it is like to be a lion or a tree" (p. 713).

Building on this argument Bonnett advances a particular metaphysical approach to environmental education, arguing that "if education is to help pupils to live in such a way that they can flourish in an authentic - that is, poetic-relationship with the self-arising, it will need to help them to learn properly to love the self-arising in themselves" (p. 719). He argues that "this requires a certain preparation of heart and mind to receive what is offered-a suspension of the mastery motive and the adoption of an attitude that is neither an indifference nor a possessive desiring, but rather a dialogical openness that incorporates a sense of the well-being of things themselves" (p. 716). 
Bonnett clearly identifies this argument as an agenda for environmental education. It seems appropriate to ask, once again, if this is the sort of lesson science educators ought to be engaged in teaching? Would his approach encourage open-mindedness? This question brings up an important distinction, as both Pedretti and Little's, and Bonnett's, approaches are insufficiently open-minded, but in different ways.

Pedretti and Little's discussion risks fostering insufficiently open-minded approaches to environmental education by misleading teachers and students about the extent of disagreement over the moral status of the environment. They express their position in a way that ignores the fundamental disagreements that exist and hence encourages close-mindedness in those who take their position at face value. Bonnett, on the other hand, makes an open-minded argument that may very well foster close-mindedness in spite of his having cited and discussed alternative literature. The issue we find in Bonnett's contribution stems from what his argument implies for science education. Bonnett's proposed mandate of promoting "a right relationship with nature as the self-arising" (Bonnett, 2007, p. 719) would encourage teachers to foster this understanding, despite its contentiousness, at the expense of other perspectives. Although Bonnett's explanation of his position takes other arguments seriously, his agenda seems to encourage teachers to do quite the opposite. The particular metaphysical and ethical position he advances is, like the others cited, legitimate and often well argued. It is not, however, something that should be taught at the expense of the opportunity of students to develop what Bonnett would consider wrong dispositions to nature.

Although science is not value-free, open-minded science education requires a distinction between scientific claims and moral or ethical claims. Science takes no stand on the moral status of the environment, seeking instead to describe and explain environmental states. From a scientific perspective the state of the Earthly environment at the time when its atmosphere was a noxious stew of steaming gases is no better or worse morally than the current state. Science will say that one state is better or worse, or more or less hospitable, for mammalian life, let us say, but such judgments do not imply a moral position. Rather they are about causal efficacy. Thus, attempts at making "appreciation" or moral-valuing desirable outcomes of environmental education in science can be interpreted only as attempts to press a particular moral agenda onto students. Should students hold the environment in high esteem or view it as a mere instrumental collection of resources? Presumably, the latter alternative would be suppressed under the goals set forth by both perspectives we have discussed.

Bonnett would likely take issue with this understanding of science, as it would indicate to him a "largely analytic/instrumental/invasive rationality" (2007, p. 708), a view he deplores. His proposed solution to the dominance of this perspective, though, is the infusion of a set of metaphysical and ethical assertions into science teaching that seem totally outside the realm of science. There is much truth in the maxim that science can describe but not prescribe. We recognize that science embodies prescriptive norms, but these norms properly refer to the practice of science, and are themselves open to critique and revision. The norm of objectivity, for instance, calls for those who claim to conduct science to aspire to this ideal in their practice of science. Such norms can be used to prescribe wider norms about good living, as is the case in Bonnett's conception, but one who does so has stepped outside the proper realm of science.

On this disagreement one important note must be made. As was indicated in our discussion of Hare's work, there is nothing close-minded about posing an argument about what should be taught and what should not. The moral educational philosopher who advocates deontological forms of moral education over virtue-ethical ones, for example, is not prima facie behaving in a close-minded fashion. As a normative rival to other approaches to moral or spiritual education, Bonnett's position is fully legitimate. We would argue, though, that mandating science education to actively advance one set of metaphysical assumptions is insufficiently open-minded. The science classroom must have room for the student who accepts Bonnett's position as well as the student who does not.

There are cases, then, where environmental education literature reflects a disregard for alternative viewpoints that is concerning, and cases where it recommends practices that would promote 
this disposition in teachers and students. Using Hare's terminology, we have discussed approaches that are insufficiently open-minded both in terms of their treatment of alternatives and in terms of their recommendations for teaching. A fully open-minded environmental education would surely allow students to decide how, why, and whether the environment might be valued or appreciated.

\section{Conclusion}

There is some environmental education literature that reflects precisely the open-minded model we argue science education requires. Perhaps the best recent example is provided by Jickling and Wals (2008). They note that skeptics, like themselves, "see a downside to the homogenizing tendencies of these global policy movements and take offence at prescriptive constructions such as 'education for sustainable development' that reduce the conceptual space for self-determination, autonomy, and alternative ways of thinking" (Jickling \& Wals, 2008, p. 4). These authors indicate a similar position to the one we advocate, and we can surmise that they might very well agree with our assessment that the value-endorsing approaches canvassed here foster close-mindedness. They note that much of the discussion of these issues tends to center on how best to foster the assumptions of a particular agenda, rather than being a discussion of the agenda itself. They advocate, once again in concert with our argument, that "environmental education, is not just about social reproduction, but also, and perhaps foremost, about creating the ability to critique and transcend social norms, patterns of behaviour and lifestyles without authoritatively prescribing alternative norms, behaviours and lifestyles" (Jickling \& Walls, 2008, p. 7). Michael Reiss (2000), in his discussion of teaching science in multicultural societies, asks whether we as educators are looking to produce particular positive behaviours or to foster autonomy. Scholars like Jickling and Wals remind us that issues like sustainable development are sufficiently contentious that fostering autonomy is the only defensible answer.

Science education may approach key problems from an open-minded perspective without hindering its ability to empower students to address pressing public issues. Indeed, it is difficult to understand how one might conceive of empowerment without the ability to make open-minded decisions. Early in our discussion we cited Hare's understanding of open-mindedness as the disposition and ability to revise one's beliefs. There are a worrying number of scholarly contributions and resources that appear actively to restrict the capacity of science education to foster open-mindedness. Although these contributions often express legitimate, and valuable, perspectives they advance them as the natural perspectives for students to adopt. Although many of these contributors claim merely to be presenting one side of an issue, it is nonetheless the case that their solutions encourage the exclusion of particular legitimate perspectives and thereby encourage close-mindedness in science education. Hare is most certainly right when he and McLaughlin remind us that even if we were to agree about the teaching of a particular belief we would still desire students rationally to accept it (Hare \& McLaughlin, 1998), and that can occur only in the context of open-minded consideration of alternatives.

\section{References}

Aristotle. (1953). The Nicomachean etbics (J.A.K. Thomson, Trans.). London: Penguin Books.

Aikenhead, G.S. (1990). Scientific/technological literacy, critical reasoning, and classroom practice. in P. Norris \& L.M. Phillips (Eds.), Foundations of literacy policy in Canada (pp. 127-145). Calgary, AB: Detselig.

Blanchet-Cohen, N. (2008). Taking a stance: Child agency across the dimensions of early adolescents' environmental involvement. Environmental Education Research, 14(3), 257-272.

Bonnett, M. (2007). Environmental education and the issue of nature. Journal of Curriculum Studies, 39(6), 
707-721.

Brennan, A., \& Lo, Y.S. (2008). Environmental ethics. In E.N. Zalta (Ed.), Stanford Encyclopedia of Philosophy. Retrieved August 4, 2008 from http://plato.stanford.edu/entries/ethics-environmental/\#Rel

Chawla, L., \& Flanders Cushing, D. (2007). Education for strategic environmental behavior. Environmental Education Research, 13(4), 437-452.

Eames, C., Brownwen, C., \& Bolstad, R. (2008). An evaluation of characteristics of environmental education practice in New Zealand schools. Environmental Education Research, 14(1), 35-51.

Ferreira, J., Ryan, L., \& Tillbury, D. (2007). Mainstreaming education for sustainable development in initial teacher education in Australia: A review of existing professional development models. Journal of Education for Teaching: International Research and Pedagogy, 33(2), 225-239.

Gruen, L. (2003). The moral status of animals. In E.N. Zalta (Ed.), Standford Encyclopedia of Philosophy. Retrieved August 11, 2008, from http://plato.stanford.edu/entries/moral-animal/

Harding, P., \& Hare, W. (2000). Portraying science accurately in classrooms: Emphasizing openmindedness rather than relativism. Journal of Research in Science Teaching, 37(3), 225-236.

Hare, W. (2002). Teaching and the attitude of open-mindedness. Journal of Educational Administration and Foundations, 16(2), 103-124.

Hare, W. (2000). Teaching and the barricades to inquiry. The Journal of General Education, 49(2), 88-109.

Hare, W., \& Mclaughlin, T. (1998). Four anxieties about open-mindedness: Reassuring Peter Gardner. Journal of Philosophy of Education, 32(2), 283-292.

Hare, W. (1979). Open-mindedness and education. Montreal: McGill-Queen's University Press.

Jickling, B., \& Wals, J. (2008). Globalization and environmental education: Looking beyond sustainable development. Journal of Curriculum Studies, 40(1), 1-21.

Kitchener, R. (1992). Piaget's genetic epistemology: Epistemological implications for science education. In R. Duschl \& R. Hamiton (Eds.), Philosophy of science, cognitive psychology, and education theory and practice (pp. 11-33). Albany, NY: State University of New York Press.

Munby, H. (1980). Analysing teaching for intellectual independence. In H. Munby, G. Orpwood, \& T. Russell (Eds.), Seeing curriculum in a new light (pp. 11-33). Toronto: OISE Press.

Norris, S.P. (1997). Intellectual independence for nonscientists and other content-transcendent goals of science education. Science Education, 81(2), 239-258.

Nuyen, A. (2008). Ecological education: What resources are there in Confucian ethics? Environmental Education Research, 14(2), 187-197.

Pedretti, E., \& Little, C. (2008). From engagement to empowerment: Reflections on science education for Ontario. Toronto: Pearson.

Reiss, M. (2000). Teaching science in a multicultural, multi-faith society. In J. Sears \& P. Sorenson (Eds.), Issues in science teaching (pp. 16-22). London: Routledge Falmer.

Stoss, F. (2008, April). If we are so smart, why do we need environmental education?. Electronic Green Journal, 1(26), 1-3.

UNESCO (n.d.). UN decade for education for sustainable development. Accessed August 1, 2008, from http://portal.unesco.org/education/en/ev.phpURL_ID=23279\&URL_DO=DO_TOPIC\&URL_SECTION=201.html

\section{About the Authors}

David P. Burns is a Ph.D. student and sessional instructor and Stephen P. Norris is Professor and

Canada Research Chair in the Department of Educational Policy Studies, University of Alberta. David can be reached atdburns@ualberta.ca and Stephen can be reached at stephenn@ualberta.ca 